\title{
A Role for the Small Molecular Weight GTPases, Rho and Cdc42, in Muscarinic Receptor Signaling to Focal Adhesion Kinase
}

\author{
Daniel A. Linseman, *Fred Hofmann, and Stephen K. Fisher \\ Department of Pharmacology and Neuroscience Laboratory, Mental Health Research Institute, University of Michigan, Ann \\ Arbor, Michigan, U.S.A.; and *Institut für Pharmakologie und Toxikologie, Albert-Ludwigs-Universität, Freiburg, Germany
}

\begin{abstract}
An enhanced tyrosine phosphorylation of focal adhesion kinase (FAK) is elicited during neuronal growth cone remodeling and requires the maintenance of agonist-sensitive pools of phosphatidylinositol 4,5-bisphosphate $\left(\mathrm{PIP}_{2}\right)$. Rho family GTPases are putative regulators of both $\mathrm{PIP}_{2}$ synthesis and growth cone remodeling, including neurite outgrowth elicited by muscarinic cholinergic receptor (mAChR) stimulation. In this study, we investigated the interrelationships among Rho family GTPases, PIP 2 synthesis, and $\mathrm{mAChR}$ signaling to FAK in $\mathrm{SH}-\mathrm{SY} 5 Y$ neuroblastoma cells. Preincubation with $\mathrm{Clos}-$ tridium difficile toxin B (Tox B), an inhibitor of Rho, Rac, and Cdc42, attenuated mAChR-stimulated FAK and paxillin tyrosine phosphorylation and lysophosphatidic acid (LPA)-induced FAK phosphorylation to a similar extent (75\% decreases at $200 \mathrm{pg} / \mathrm{ml}$ Tox B) but did not affect mitogen-activated protein kinase activation elicited by either phorbol ester or an mAChR agonist. In contrast, preincubation with selective inhibitors of either Rho (C3 exoenzyme) or Rho kinase (HA-1077) resulted in 80-90\% reductions in LPA-induced FAK phosphorylation but only 40-50\% decreases in mAChR-stimulated phosphorylation. Moreover, mAChR-mediated FAK phosphorylation was significantly attenuated in cells scrape-loaded with dominant-negative N17Cdc42 but not N17Rac1. Tox B had little or no effect on agonist-sensitive pools of $\mathrm{PIP}_{2}$ but inhibited mAChR-driven actin cytoskeletal remodeling. The results suggest that the Rho family GTPases, Rho and Cdc42, link mAChR stimulation to increases in FAK phosphorylation independently of effects on $\mathrm{PIP}_{2}$ synthesis. Key Words: Clostridium difficile toxin B-Clostridium botulinum C3 exoenzyme-Phosphatidylinositol 4,5-bisphosphate-Actin cytoskeleton-Growth cone remodeling.

J. Neurochem. 74, 2010-2020 (2000).
\end{abstract}

The signal transduction machinery that couples extracellular stimuli such as neurotransmitter release to changes in synaptic strength is presently unclear. Tyrosine kinase activity is a requirement for both long-term potentiation (O'Dell et al., 1991) and long-term depression (Boxall et al., 1996), two models of synaptic plas- ticity. Focal adhesion kinase (FAK) is a nonreceptor protein tyrosine kinase that is highly expressed in the central nervous system, where it is localized in part to neuronal growth cones (Burgaya et al., 1995; Worley and Holt, 1996). A potential role for FAK in the regulation of synaptic plasticity has recently been reviewed (Girault et al., 1999). In neuronal cells in culture, FAK is activated by stimuli that elicit growth cone remodeling. For example, neurite outgrowth induced by neural cell adhesion molecules (NCAMs) is associated with complex formation between FAK, NCAM-140, and fyn tyrosine kinase (Beggs et al., 1997). In addition, treatment of SH-SY5Y neuroblastoma cells with either insulin-like growth factor-I (Leventhal et al., 1997) or muscarinic cholinergic receptor (mAChR) agonists (Rösner et al., 1995 ) induces neurite outgrowth and an increase in the tyrosine phosphorylation of FAK (Leventhal et al., 1997; Linseman et al., 1998). Given the potential role of FAK in signaling during growth cone remodeling, it is important to understand how the above stimuli lead to an activation of FAK.

Small molecular weight $G$ proteins of the Rho family act as critical regulators of actin cytoskeletal dynamics

Received October 15, 1999; revised manuscript received January 7 , 2000; accepted January 10, 2000.

Address correspondence and reprint requests to Dr. S. K. Fisher at Neuroscience Laboratory, University of Michigan, 1103 E. Huron St., Ann Arbor, MI 48104-1687, U.S.A. E-mail: skfisher@umich.edu

Abbreviations used: BSA, bovine serum albumin; DMEM, Dulbecco's modified Eagle's medium; ERK, extracellular signal-regulated kinase; FAK, focal adhesion kinase; FCS, fetal calf serum; GPCR, G protein-coupled receptor; GST, glutathione $S$-transferase; LPA, lysophosphatidic acid; mAChR, muscarinic cholinergic receptor; MAPK, mitogen-activated protein kinase; NCAM, neural cell adhesion molecule; Oxo-M, $N, N, N$-trimethyl-4-(2-oxo-1-pyrrolidinyl)-2-butyn-1-ammonium iodide; PA, phosphatidic acid; PBS, phosphate-buffered saline; PBS-T, PBS with $0.1 \%$ Tween 20; PI, phosphatidylinositol; PILO, pilocarpine; PIP, phosphatidylinositol 4-phosphate; $\mathrm{PIP}_{2}$, phosphatidylinositol 4,5-bisphosphate; PMA, phorbol 12-myristate 13-acetate; PTyr, phosphotyrosine; PVDF, polyvinylidene difluoride; SDS-PAGE, sodium dodecyl sulfate-polyacrylamide gel electrophoresis; TCA, trichloroacetic acid; Tox B, toxin B from Clostridium difficile; WT, wortmannin. 
(for review, see Hall, 1998), and in neuronal cells, Rho family GTPases mediate changes in growth cone morphology (Luo et al., 1996; Threadgill et al., 1997). Kozma et al. (1997) have shown that Rac and Cdc42 facilitate neurite outgrowth elicited by $\mathrm{mAChR}$ stimulation, whereas Rho and activators of Rho such as lysophosphatidic acid (LPA) induce neurite retraction (see also Kranenburg et al., 1999). In addition, Rho has been implicated in FAK signaling by several G proteincoupled receptor (GPCR) agonists (for review, see Seasholtz et al., 1999), and scrape-loading cells with constitutively active Rho stimulates an enhanced tyrosine phosphorylation of FAK (Flinn and Ridley, 1996). The mechanisms underlying Rho family $\mathrm{G}$ protein regulation of the actin cytoskeleton are complex and involve multiple downstream effectors of these GTPases (for review, see Mackay and Hall, 1998). The pathway leading from Rho GTPases to activation of FAK is even less clear. One way by which Rho family GTPases may be linked to FAK signaling is via the regulation of polyphosphoinositide synthesis by Rho family members (Carpenter, 1996; Ren and Schwartz, 1998). Both Rho and Rac have been shown to regulate the synthesis of phosphatidylinositol 4,5-bisphosphate $\left(\mathrm{PIP}_{2}\right)$ in a cell-type specific manner (Chong et al., 1994; Hartwig et al., 1995). PIP regulates the actin cytoskeleton as well as many actinassociated protein-protein interactions (for review, see Toker, 1998; Martin, 1998). Recently, we have demonstrated a novel requirement for agonist-sensitive pools of $\mathrm{PIP}_{2}$ in the enhanced tyrosine phosphorylation of FAK elicited by agonists at phosphoinositide-linked receptors such as the $\mathrm{M}_{3}$ mAChR (Linseman et al., 1999). The focus of the current study was to examine the interrelationships of Rho family G protein function, inositol lipid synthesis, and FAK signaling by addressing two principal questions: (1) Do Rho family G proteins regulate FAK signaling elicited by mAChR stimulation, and, if so, (2) is this regulation dependent on a modulation of agonist-sensitive $\mathrm{PIP}_{2}$ pools?

To address the above questions, we utilized selective inhibitors of Rho family $\mathrm{G}$ protein function. Toxin B from Clostridium difficile (Tox B) is a monoglucosyltransferase that selectively inhibits Rho, Rac, and Cdc42 without affecting other small molecular weight GTPases (Just et al., 1995). In contrast, C3 exoenzyme from $C$. botulinum specifically ADP-ribosylates and inactivates Rho (Aktories et al., 1989; Braun et al., 1989). The results of the current study demonstrate that an increased tyrosine phosphorylation of FAK elicited in SH-SY5Y neuroblastoma cells by either LPA or an mAChR agonist is significantly inhibited by Tox B. Although LPAinduced FAK phosphorylation is equally sensitive to inhibition by either Tox B or $\mathrm{C} 3$ exoenzyme, mAChRmediated FAK phosphorylation is much less sensitive to inhibition by $\mathrm{C} 3$ exoenzyme (or to an inhibitor of Rho kinase activity, HA-1077), suggesting the involvement of a C3 exoenzyme-insensitive Rho family member in the signaling pathway. This suggestion was confirmed by the observation that scrape-loading cells with dominant- negative N17Cdc42 (but not N17Rac1) significantly attenuated the mAChR-induced FAK phosphorylation. Finally, inhibition of Rho family GTPase function by Tox B suppressed mAChR-mediated FAK phosphorylation and actin cytoskeletal remodeling independently of effects on mAChR-sensitive $\mathrm{PIP}_{2}$ pools. The results suggest that the Rho family GTPases, Rho and Cdc42, link mAChR stimulation to FAK phosphorylation via a mechanism that is distinct from a modulation of $\mathrm{PIP}_{2}$ synthesis.

\section{EXPERIMENTAL PROCEDURES}

\section{Materials}

Phorbol 12-myristate 13-acetate (PMA), PD-98059, HA1077, and C3 exoenzyme from C. botulinum were obtained from Calbiochem (San Diego, CA, U.S.A.). Wortmannin (WT), pilocarpine (PILO), and LPA were from Sigma Chemical Co. (St. Louis, MO, U.S.A.). N,N,N-Trimethyl-4-(2-oxo-1-pyrrolidinyl)-2-butyn-1-ammonium iodide (Oxo-M) was purchased from Research Biochemicals International (Natick, MA, U.S.A.). Tox B was a gift from Dr. Klaus Aktories (Institut für Pharmakologie und Toxikologie, Albert-Ludwigs-Universität, Freiburg, Germany). [ $\left.{ }^{32} \mathrm{P}\right]$ Orthophosphoric acid $(10 \mathrm{mCi} / \mathrm{ml})$, myo- $\left[2-{ }^{3} \mathrm{H}\right]$ inositol $(1 \mathrm{mCi} / \mathrm{ml})$, reagents for enhanced chemiluminescence, and peroxidase-conjugated sheep anti-mouse IgG were purchased from Amersham Corp. (Arlington Heights, IL, U.S.A.). $\left[{ }^{32} \mathrm{P}\right] \mathrm{NAD}(2 \mathrm{mCi} / \mathrm{ml})$ was from New England Nuclear (Boston, MA, U.S.A.). Monoclonal antibody to phosphotyrosine (PTyr) was obtained from Upstate Biotechnology (Lake Placid, NY, U.S.A.). Monoclonal antibody to paxillin was from Transduction Laboratories (Lexington, KY, U.S.A.). Polyclonal antibody to FAK, peroxidase-conjugated goat antirabbit IgG, purified glutathione $S$-transferase (GST), and agarose-conjugated protein A/G were obtained from Santa Cruz Biotechnology (Santa Cruz, CA, U.S.A.). Polyclonal antibody to the dually phosphorylated (active) forms of the extracellular signal-regulated kinases ERK-1 and ERK-2 was purchased from Promega (Madison, WI, U.S.A.). Rhodamine-conjugated phalloidin was from Molecular Probes (Eugene, OR, U.S.A.). Human recombinant GST fusion proteins of (dominant-negative) N17Rac1 and N17Cdc42 were obtained from Cytoskeleton (Denver, CO, U.S.A.). Tissue culture supplies were purchased from Corning Glass Works (Corning, NY, U.S.A.) and Sarstedt (Newton, NC, U.S.A.). Dulbecco's modified Eagle's medium (DMEM) was obtained from GIBCO (Grand Island, NY, U.S.A.). Fetal calf serum (FCS) was from Summit Biotechnology (Ft. Collins, CO, U.S.A.). Human SH-SY5Y neuroblastoma cells were obtained from Dr. June Biedler (SloanKettering Institute, New York, NY, U.S.A.).

\section{Cell culture conditions}

Human SH-SY5Y neuroblastoma cells (passages 70-78) were routinely grown in $75-\mathrm{cm}^{2}$ tissue culture flasks containing $20 \mathrm{ml}$ of DMEM supplemented with 10\% FCS. Cells were grown for $7-14$ days at $37^{\circ} \mathrm{C}$ in a humidified atmosphere consisting of $90 \%$ air and $10 \% \mathrm{CO}_{2}$. Cells were subcultured into 35-mm-diameter, six-well culture plates (Becton Dickinson Labware, Lincoln Park, NJ, U.S.A.) for 2-5 days before treatment. All experiments were performed on cells that had reached confluency, except F-actin staining, which was performed on cells that were $\sim 30-50 \%$ confluent. 
Incubation conditions and immunoprecipitations

Confluent cultures of SH-SY5Y cells were preincubated for $\sim 24 \mathrm{~h}$ in culture medium containing either vehicle $[0.1 \%$ bovine serum albumin (BSA) in phosphate-buffered saline (PBS)] or Tox B at a final concentration of 50,100, or 200 $\mathrm{pg} / \mathrm{ml}$. Following the preincubation period, cells were washed once with $2 \mathrm{ml}$ of prewarmed $\left(37^{\circ} \mathrm{C}\right)$ treatment buffer consisting of $138 \mathrm{~m} M \mathrm{NaCl}, 6 \mathrm{~m} M \mathrm{KCl}, 1 \mathrm{~m} M \mathrm{MgCl}_{2}, 1 \mathrm{~m} M \mathrm{CaCl}_{2}$, $1 \mathrm{~m} M \mathrm{Na}_{2} \mathrm{HPO}_{4}, 5 \mathrm{~m} M \mathrm{NaHCO}_{3}, 5.5 \mathrm{~m} M$ glucose, and $20 \mathrm{~m} M$ HEPES (pH 7.4) and allowed to equilibrate at $37^{\circ} \mathrm{C}$ in $1 \mathrm{ml}$ of treatment buffer for $20 \mathrm{~min}$. Alternatively, some cultures were preincubated for $30 \mathrm{~min}$ with $50 \mu M \mathrm{HA}-1077$. Cells were then incubated for a further $10 \mathrm{~min}$ with either Oxo-M, PILO, or LPA as described in the text. Following treatment, the buffer was aspirated and cells were rinsed once with $2 \mathrm{ml}$ of ice-cold PBS (pH 7.4) lacking calcium or magnesium. Cells were then placed on ice and scraped into lysis buffer $(200 \mu \mathrm{l} /$ well $)$ containing $20 \mathrm{~m} M$ HEPES ( $\mathrm{pH} 7.4$ ), $1 \%$ Triton X-100, $50 \mathrm{~m} M$ $\mathrm{NaCl}, 1 \mathrm{~m} M$ EGTA, $5 \mathrm{~m} M \beta$-glycerophosphate, $30 \mathrm{~m} M$ sodium pyrophosphate, $100 \mu M$ sodium orthovanadate, $1 \mathrm{~m} M$ phenylmethylsulfonyl fluoride, $10 \mu \mathrm{g} / \mathrm{ml}$ aprotinin, and $10 \mu \mathrm{g} / \mathrm{ml}$ leupeptin. Cell debris was removed by centrifugation at 6,000 $g$ for $3 \mathrm{~min}$, and the protein concentration of the supernatant was determined using a commercially available protein assay kit (Pierce Chemical Co., Rockford, IL, U.S.A.). Aliquots $(\sim 350 \mu \mathrm{g})$ of supernatant protein were transferred to tubes containing either $2 \mu \mathrm{g}$ of polyclonal anti-FAK or $1 \mu \mathrm{g}$ of monoclonal anti-paxillin. Samples were then immunoprecipitated at $4^{\circ} \mathrm{C}$ for $16-20 \mathrm{~h}$ with continuous mixing. Agaroseconjugated protein A/G (20 $\mu \mathrm{l})$ was added for an additional $4 \mathrm{~h}$ with mixing. Immune complexes were pelleted by centrifugation and washed three times with ice-cold lysis buffer. The final agarose pellet was resuspended in an equal volume of $2 \times$ sodium dodecyl sulfate-polyacrylamide gel electrophoresis (SDS-PAGE) sample buffer, boiled for $5 \mathrm{~min}$, and electrophoresed through $7.5 \%$ polyacrylamide gels. Proteins were transferred to polyvinylidene difluoride (PVDF) membranes (Millipore Corp., Bedford, MA, U.S.A.) and processed for immunoblot analysis.

\section{Immunoblot analysis}

Nonspecific binding sites were blocked in PBS (pH 7.4) containing $0.1 \%$ Tween 20 (PBS-T) and 1\% BSA for $1 \mathrm{~h}$ at room temperature. Primary antibodies were diluted in blocking solution $(0.5-1 \mu \mathrm{g} / \mathrm{ml})$ and incubated with the membranes for $1 \mathrm{~h}$. Excess primary antibody was removed by washing the membranes three times in PBS-T. The blots were then incubated in peroxidase-conjugated secondary antibody diluted in PBS-T $(1: 10,000)$ for $1 \mathrm{~h}$ and subsequently washed three times in PBS-T. Immunoreactive proteins were detected by enhanced chemiluminescence. Quantitative analysis of autoluminograms was performed by computer-assisted imaging densitometry (MCID; Imaging Research, St. Catharines, Ontario, Canada).

\section{Measurement of mitogen-activated protein kinase (MAPK) activation}

Confluent cultures of SH-SY5Y cells were preincubated with either vehicle or Tox B as described above. Alternatively, some cultures were preincubated for $10 \mathrm{~min}$ with $10 \mu M$ PD-98059. Following preincubation, the cells were treated for a further $10 \mathrm{~min}$ with either buffer, Oxo-M (1 mM), or PMA $(100 \mathrm{n} M)$. Lysates $(100 \mu \mathrm{g})$ were electrophoresed through $10 \%$ polyacrylamide gels and immunoblotted with an antibody that recognizes the dually phosphorylated (active) forms of ERK-1 and ERK-2.

\section{Scrape-loading with C3 exoenzyme}

Confluent dishes (6-cm diameter) of SH-SY5Y cells were scraped into culture medium containing $12.5 \mu \mathrm{g} / \mathrm{ml} \mathrm{C} 3$ exoenzyme. Cells scraped in the presence of medium alone served as a control. To ensure that cells that were to be treated with either Oxo-M (or PILO) or LPA had been exposed to equivalent scrape-loading with $\mathrm{C} 3$ exoenzyme, each 6-cm dish was equally dispersed into three 35 -mm-diameter wells and allowed to incubate for $\sim 24 \mathrm{~h}$ at $37^{\circ} \mathrm{C} / 10 \% \mathrm{CO}_{2}$. Following preincubation, each of the three wells was treated with either buffer, Oxo-M or PILO $(1 \mathrm{~m} M)$, or LPA $(10 \mu M)$ for $10 \mathrm{~min}$. Lysates were collected, and FAK was immunoprecipitated as described above.

\section{Scrape-loading with GST fusion proteins}

Either GST alone or GST fusion proteins (N17Rac1 or N17Cdc42) were scrape-loaded into cells at a concentration of $20 \mu \mathrm{g} / \mathrm{ml}$ essentially as described (Flinn and Ridley, 1996). Following $30 \mathrm{~min}$ of preincubation, cells were treated with either buffer or Oxo-M $(1 \mathrm{~m} M)$ for $10 \mathrm{~min}$. Lysates were collected, and FAK was immunoprecipitated as described above.

\section{C3 exoenzyme-catalyzed ADP-ribosylation of Rho proteins}

In vitro ADP-ribosylation of Rho proteins in SH-SY5Y lysates obtained from cells preincubated with either vehicle or Tox B was accomplished by incubation for $1 \mathrm{~h}$ at $30^{\circ} \mathrm{C}$ in the presence of $1 \mu \mathrm{g}$ of $\mathrm{C} 3$ exoenzyme and $5 \mu \mathrm{Ci}$ of $\left[{ }^{32} \mathrm{P}\right] \mathrm{NAD}$ as previously described (Yamamoto et al., 1993). Reactions were terminated by boiling in SDS-PAGE sample buffer. Proteins were electrophoresed through $12.5 \%$ polyacrylamide gels and transferred to PVDF membranes. Incorporation of $\left.{ }^{32} \mathrm{P}\right] \mathrm{ADP}-$ ribose into Rho proteins was determined by phosphorimager analysis (Cyclone Storage Phosphor System; Packard Instrument Company, Meriden, CT, U.S.A.).

\section{Measurement of phosphoinositide turnover and $\left[{ }^{3} \mathrm{H}\right]$ inositol lipids}

Confluent cultures of SH-SY5Y cells were prelabeled for $48 \mathrm{~h}$ in culture medium containing $10 \mu \mathrm{Ci} / \mathrm{ml}\left[{ }^{3} \mathrm{H}\right]$ inositol, followed by the addition of either vehicle $(0.1 \%$ BSA in PBS) or Tox B $(200 \mathrm{pg} / \mathrm{ml})$ and incubation for a further $24 \mathrm{~h}$. Following preincubation, cells were treated in the presence of $30 \mathrm{mM} \mathrm{LiCl}$ for $30 \mathrm{~min}$ at $37^{\circ} \mathrm{C}$ with either buffer or $1 \mathrm{mM}$ Oxo-M. Reactions were terminated by the addition of chloroform/methanol. The accumulation of radiolabeled inositol phosphates in the aqueous fraction was determined as previously described (Thompson and Fisher, 1990). Lipids were extracted from the organic fraction, and phospholipids were separated on oxalate-impregnated TLC plates. Plates were sprayed with $\mathrm{EN}^{3} \mathrm{HANCE}$ (New England Nuclear, Boston, MA, U.S.A.) to visualize ${ }^{3} \mathrm{H}$-labeled lipids, which were then quantitated by liquid scintillation counting.

\section{Phospholipid labeling from ${ }^{32} \mathbf{P}_{\mathbf{i}}$}

SH-SY5Y cells that had been preincubated with either vehicle or Tox B for $24 \mathrm{~h}$ were incubated to isotopic equilibrium at $37^{\circ} \mathrm{C}$ in $1 \mathrm{ml}$ of phosphate-free treatment buffer containing $10 \mu \mathrm{Ci} / \mathrm{ml}^{32} \mathrm{P}_{\mathrm{i}}$ for $2-4 \mathrm{~h}$. The labeling solution was aspirated, and unincorporated ${ }^{32} \mathrm{P}_{\mathrm{i}}$ was removed by washing with $2 \mathrm{ml}$ of the same buffer. Some cultures were then incubated for $10 \mathrm{~min}$ with WT $(10 \mu M)$, and the cells were then treated for a further 10 min with either buffer or Oxo-M. Incubations were terminated by rapid aspiration of the treatment solution followed by 
addition of $0.5 \mathrm{ml}$ of ice-cold 5\% trichloroacetic acid (TCA). Cells were scraped into TCA on ice, transferred to glass tubes with an additional $1 \mathrm{ml}$ of 5\% TCA, and allowed to precipitate on ice for $1 \mathrm{~h}$. Pellets were obtained by centrifugation at $4^{\circ} \mathrm{C}$ and washed once with $2 \mathrm{ml}$ of ice-cold distilled water, and the final TCA pellet was resuspended in $0.5 \mathrm{ml}$ of water. Lipids were extracted from the pellets with acidified chloroform/ methanol as previously described (Fisher and Agranoff, 1980). Phospholipids were then separated on oxalate-impregnated TLC plates and quantified according to a previously published method (Fisher et al., 1984).

\section{Rhodamine/phalloidin staining of F-actin}

SH-SY5Y cells seeded on glass coverslips were preincubated for $24 \mathrm{~h}$ in medium containing either vehicle or Tox B $(200 \mathrm{pg} / \mathrm{ml})$. Following preincubation, the cells were then treated for $5 \mathrm{~min}$ with either buffer or Oxo-M. The treatment solution was aspirated, and the cells were fixed for $30 \mathrm{~min}$ in $4 \%$ paraformaldehyde in PBS. Cells were permeabilized for 30 min in PBS containing $0.2 \%$ Triton $\mathrm{X}-100$ and $5 \%$ BSA and incubated for a further $30 \mathrm{~min}$ with rhodamine/phalloidin ( $\sim 100 \mathrm{n} M$ final concentration) in PBS containing $2 \%$ BSA and $0.2 \%$ Triton X-100. Coverslips were adhered to slides, and cell fluorescence was visualized using a Leitz Aristoplan epifluorescence microscope.

\section{Data analysis}

Results shown represent the mean \pm SEM values for the number (n) of independent experiments performed. Statistical differences between the means of unpaired sets of data were evaluated using the Student's two-tailed $t$ test. When several treatments were compared, one-way ANOVA followed by a post hoc Dunnett's test was utilized to determine significant differences. A $p$ value of $<0.05$ was considered statistically significant.

\section{RESULTS}

\section{Tox B inhibits mAChR signaling to FAK and paxillin}

Previous work by Just et al. (1994) demonstrated that monoglucosylation of Rho proteins by Tox B results in an inhibition of subsequent $\mathrm{C} 3$ exoenzyme-catalyzed ADP-ribosylation of Rho. We utilized this assay to determine the efficiency of Tox B treatment in confluent cultures of SH-SY5Y neuroblastoma cells. Preincubation of SH-SY5Y cells with Tox B resulted in a dosedependent inhibition of the subsequent $\mathrm{C} 3$ exoenzymecatalyzed ADP-ribosylation of Rho in cell lysates (Fig. 1A). The $\mathrm{IC}_{50}$ for Tox B-mediated inhibition of ADPribosylation was $\sim 100 \mathrm{pg} / \mathrm{ml}$, and at the highest Tox B concentration tested $(200 \mathrm{pg} / \mathrm{ml})$, the ADP-ribosylation of Rho was inhibited by $\sim 80 \%$ (Fig. 1B). These results demonstrate that Tox B efficiently enters intact $\mathrm{SH}$ SY5Y cells and interacts directly with Rho family G proteins in those cells.

Next, we evaluated the potential of Tox B to inhibit mAChR signaling to FAK and paxillin, a downstream cytoskeletal substrate of FAK (Schaller and Parsons, 1995). As previously reported (Linseman et al., 1998), incubation of SH-SY5Y cells with the mAChR agonist Oxo-M elicited marked increases (17- to 20-fold) in the tyrosine phosphorylation of FAK (Fig. 2A, upper panel)

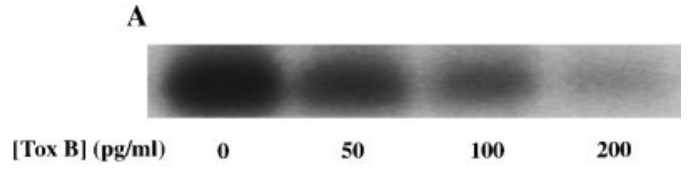

B

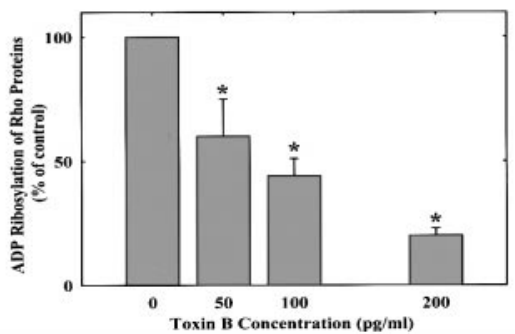

FIG. 1. Preincubation with Tox $B$ inhibits the subsequent in vitro ADP-ribosylation of Rho proteins induced by $\mathrm{C} 3$ exoenzyme. Confluent cultures of SH-SY5Y cells were preincubated for $\sim 24$ $\mathrm{h}$ in culture medium containing either vehicle (0.1\% BSA in PBS) or the indicated concentrations of Tox B. Following incubation, the cells were lysed and supernatants were incubated for $1 \mathrm{~h}$ at $30^{\circ} \mathrm{C}$ in the presence of $\mathrm{C} 3$ exoenzyme and [32P]NAD. Reactions were terminated by the addition of SDS-PAGE sample buffer, and aliquots containing equivalent amounts of protein were electrophoresed through $12.5 \%$ polyacrylamide gels. Proteins were transferred to PVDF, and ADP-ribosylation of Rho proteins was assessed by phosphorimager analysis. A: Representative autoradiogram of $A D P$-ribosylated Rho proteins following in vitro incubation with C3 exoenzyme. B: Phosphorimager analysis of the effects of preincubation with Tox $B$ on the subsequent ADPribosylation of Rho proteins. The results are expressed as a percentage of the ADP-ribosylation detected in cells preincubated with vehicle and represent the means \pm SEM of three independent experiments. ADP-ribosylation in the vehicle control measured 19,915 $\pm 4,652$ digital light units $/ \mathrm{mm}^{2}$. ${ }^{*} p<0.05$, significantly different from the vehicle control.

and paxillin (Fig. 2A, lower panel), increases that were dose dependently inhibited by preincubation with Tox B. The $\mathrm{IC}_{50}$ values for Tox B-induced inhibition of FAK and paxillin phosphorylation were both $\sim 100 \mathrm{pg} / \mathrm{ml}$, and at the highest Tox B concentration tested $(200 \mathrm{pg} / \mathrm{ml})$, the agonist-stimulated phosphorylation of these proteins was inhibited by $\sim 75 \%$ (Fig. $2 B$ ). Thus, Tox B inhibits the mAChR-stimulated tyrosine phosphorylation of FAK and paxillin with dose-inhibition curves that closely parallel the dose dependency of the Tox B interaction with Rho family $\mathrm{G}$ proteins.

\section{Tox B does not affect MAPK signaling}

An enhanced tyrosine phosphorylation of FAK has been linked to activation of the Ras/MAPK cascade via the association of FAK with the adapter protein GRB-2 (Schlaepfer et al., 1994). mAChR signaling to MAPK occurs via a protein kinase C-dependent pathway in SH-SY5Y cells (Offermanns et al., 1993). We analyzed the effects of Tox B on MAPK signaling elicited following either the stimulation of $\mathrm{mAChRs}$ or the addition of phorbol ester. SH-SY5Y cells incubated with either OxoM or PMA demonstrated a dramatic enhancement of MAPK activation as indicated by increases in the dually 


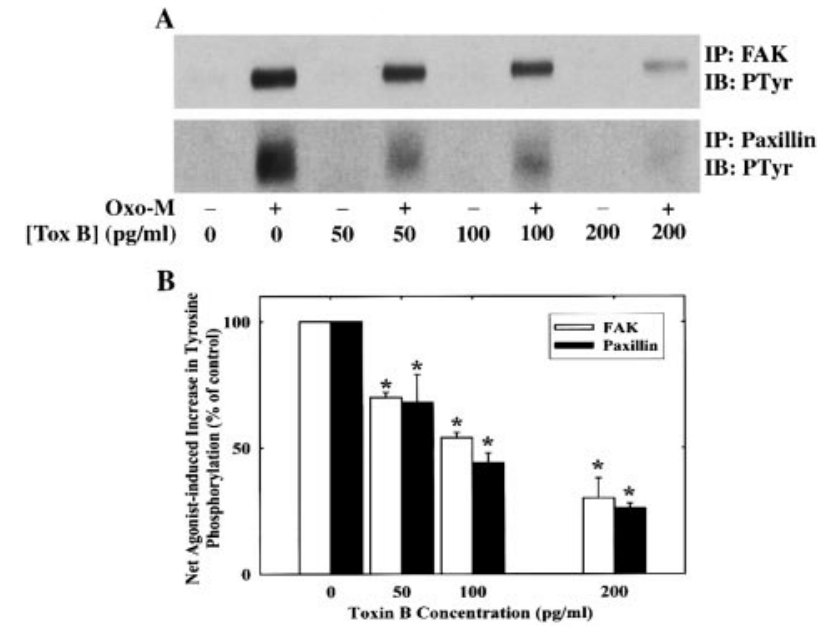

FIG. 2. Tox B dose-dependently inhibits the enhanced tyrosine phosphorylation of FAK and paxillin elicited by Oxo-M. Confluent cultures of SH-SY5Y cells were preincubated for $\sim 24 \mathrm{~h}$ in culture medium containing either vehicle (0.1\% BSA in PBS) or Tox B at the concentrations indicated. The cells were then treated for 10 min with either buffer or $1 \mathrm{mM}$ Oxo-M. A: Following incubation, cells were scraped into lysis buffer and supernatants were immunoprecipitated (IP) with either polyclonal anti-FAK (upper panel) or monoclonal anti-paxillin (lower panel), as described in Experimental Procedures. Immune complexes were resolved by SDS-PAGE, transferred to PVDF membranes, and immunoblotted (IB) for PTyr. B: Densitometric analysis of agonist-induced FAK and paxillin phosphorylation following preincubation with Tox B was performed. The results are expressed as a percentage of the net agonist-induced increase in either FAK or paxillin phosphorylation observed in cells preincubated with vehicle and represent the means \pm SEM of three independent experiments. Oxo-M addition increased the tyrosine phosphorylation of FAK in vehicle-pretreated cells from $0.04 \pm 0.01$ to $0.68 \pm 0.15$ O.D. unit and increased paxillin phosphorylation from $0.03 \pm 0.01$ to $0.60 \pm 0.16$ O.D. unit. ${ }^{*} p<0.05$, significantly different from the vehicle control.

phosphorylated forms of ERK-1 and ERK-2 (Fig. 3, lanes 1-3). Although MAPK activation elicited by either of these agents was equally susceptible to inhibition by the MAPK kinase inhibitor PD-98059 (Fig. 3, lanes 7-9), neither was affected by preincubation with $200 \mathrm{pg} / \mathrm{ml}$ Tox B (Fig. 3, lanes 4-6). These results demonstrate that the FAK and MAPK signaling pathways elicited by $\mathrm{mAChR}$ activation are clearly distinct in their dependence on Rho family $\mathrm{G}$ protein function.

\section{Inhibition of either Rho or Rho kinase function elicits differential effects on FAK phosphorylation stimulated by mAChR agonists or LPA}

LPA has previously been shown to signal to FAK through a pathway involving the small molecular weight G protein Rho (Kumagai et al., 1993). More recently, LPA has also been shown to signal through a downstream effector of Rho, Rho kinase (Maekawa et al., 1999). To determine if mAChR activation signals to FAK via a similar pathway, we utilized selective inhibitors of either Rho function (C3 exoenzyme from $C$. botulinum) or Rho kinase activity (HA-1077; Uehata et al., 1997). We have previously shown that C3 exoen- zyme treatment of intact SH-SY5Y cells had only a limited effect on mAChR-induced FAK phosphorylation (Linseman et al., 1998). However, interpretation of this latter result was complicated by the fact that $\mathrm{C} 3$ exoenzyme did not readily enter intact SH-SY5Y cells, as indicated by a partial ( $\sim 35 \%)$ ADP-ribosylation of Rho proteins (Linseman et al., 1998). In an effort to circumvent this problem, SH-SY5Y cells were scrape-loaded with C3 exoenzyme and the effects on Oxo-M- or LPAstimulated FAK phosphorylation were assessed. Scrapeloading SH-SY5Y cells with C3 exoenzyme resulted in a $51 \pm 8 \%$ ADP-ribosylation of Rho proteins $(\mathrm{n}=3, p$ $=0.05$ ). Preincubation with $\mathrm{C} 3$ exoenzyme significantly blocked the LPA-induced tyrosine phosphorylation of FAK by $\sim 80 \%$ (Fig. 4A, upper panel), a result consistent with the level of inhibition observed following Tox B pretreatment (Fig. 4B). In contrast, cells scrape-loaded with $\mathrm{C} 3$ exoenzyme responded to Oxo-M with an increase in FAK phosphorylation that was only partially blunted by $\sim 40 \%$ (Fig. 4A, upper panel) as compared with the 75\% decrease observed with Tox B (Fig. 4B). A similar differential effect was also observed in cells preincubated with the Rho kinase inhibitor HA-1077. Whereas LPA-induced FAK phosphorylation was inhibited by $\sim 90 \%$ by HA-1077, Oxo-M-stimulated FAK phosphorylation was only partially attenuated by $\sim 50 \%$ (Fig. 4A, lower panel, and B).

To verify that the differential effects observed were not due to differences in the magnitude of FAK phosphorylation elicited by Oxo-M versus LPA, we assessed the effects of $\mathrm{C} 3$ exoenzyme and HA-1077 on FAK phosphorylation elicited by either LPA or a partial mAChR agonist, PILO. PILO elicited an increase in the tyrosine phosphorylation of FAK that was equivalent to that induced by LPA (Fig. 5). However, preincubation with either C3 exoenzyme (Fig. 5, upper panel) or HA1077 (Fig. 5, lower panel) inhibited LPA-induced FAK phosphorylation to a greater extent than that elicited by PILO. Collectively, the above data suggest that the LPA receptor signals to FAK principally through a Rho/Rho

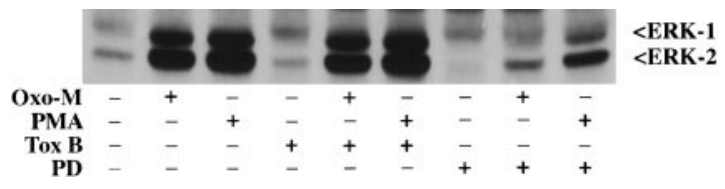

FIG. 3. Tox $B$ has no effect on MAPK activation stimulated by either Oxo-M or PMA. Confluent cultures of SH-SY5Y cells were preincubated for $\sim 24 \mathrm{~h}$ in culture medium containing either vehicle $(0.1 \%$ BSA in PBS) or Tox B $(200 \mathrm{pg} / \mathrm{ml})$. Alternatively, some cultures were preincubated for $10 \mathrm{~min}$ with $10 \mu \mathrm{M}$ PD98059 (PD). Cells were then treated for a further 10 min with either buffer, Oxo-M (1 mM), or PMA (100 $\mathrm{nM})$. Following incubation, cells were scraped into lysis buffer, supernatants containing $100 \mu \mathrm{g}$ of protein were electrophoresed through 10\% polyacrylamide gels, and proteins were transferred to PVDF membranes. The blots were probed with a polyclonal antibody that recognizes the Tyr/Thr-dually phosphorylated (active) forms of ERK-1 and ERK-2. The blot shown is representative of two independent experiments that demonstrated similar results. 


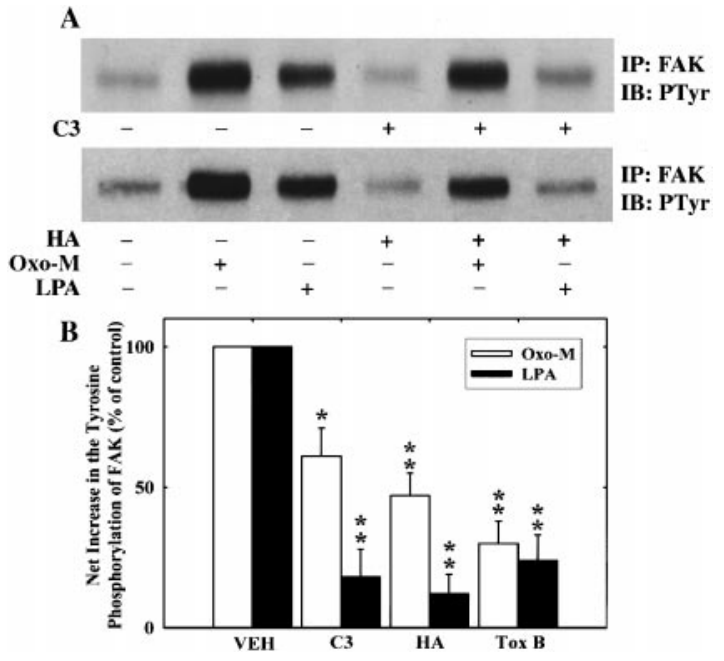

FIG. 4. Differential effects of scrape-loaded C3 exoenzyme and the Rho kinase inhibitor HA-1077 on the enhanced tyrosine phosphorylation of FAK elicited by Oxo-M and LPA. A: Confluent cultures of SH-SY5Y cells were either scrape-loaded with $\mathrm{C} 3$ exoenzyme $(12.5 \mu \mathrm{g} / \mathrm{ml}$ ) (upper panel) or preincubated with 50 $\mu M$ HA-1077 (HA) (lower panel), as described in Experimental Procedures. Following either scrape-loading with C3 exoenzyme (24 h) or preincubation with HA-1077 (30 min), the cells were treated for a further $10 \mathrm{~min}$ with either buffer, Oxo-M (1 mM), or LPA $(10 \mu M)$. Cells were scraped into lysis buffer, and supernatants were immunoprecipitated (IP) with polyclonal anti-FAK, as described in Experimental Procedures. Immune complexes were resolved by SDS-PAGE, transferred to PVDF membranes, and immunoblotted (IB) for PTyr. B: Densitometric analysis of FAK tyrosine phosphorylation was performed. The results are expressed as a percentage of the net increase in FAK phosphorylation induced by each agent in the absence of either C3 exoenzyme or HA-1077 and represent the means \pm SEM of three independent experiments. The results obtained in cells preincubated for $24 \mathrm{~h}$ with $200 \mathrm{pg} / \mathrm{ml}$ Tox B are also shown for comparison. Addition of Oxo-M or LPA increased the tyrosine phosphorylation of FAK in vehicle (VEH) control cells from 0.06 \pm 0.02 to $0.55 \pm 0.13$ or $0.29 \pm 0.10$ O.D. unit, respectively. ${ }^{*} p$ $<0.05,{ }^{* *} p<0.01$, significantly different from the control.

kinase-dependent pathway, but that $\mathrm{mAChR}$ signaling to FAK may require Rho/Rho kinase as well as another small molecular weight $\mathrm{G}$ protein that is Tox B-sensitive but $\mathrm{C} 3$ exoenzyme-insensitive.

\section{Inhibition of Cdc42 function attenuates $\mathrm{mAChR}$ signaling to FAK}

Both Rac and Cdc42 fit the criteria of Tox B-sensitive but $\mathrm{C} 3$ exoenzyme-insensitive. To determine if either of these small GTPases is involved in $\mathrm{mAChR}$ signaling to FAK, dominant-negative GST fusion proteins of each of these $\mathrm{G}$ proteins were scrape-loaded into cells, and the effects on Oxo-M-induced FAK phosphorylation were assessed. In comparison with cells scrape-loaded with GST alone, N17Rac1 had no consistent effect on mAChR-mediated FAK phosphorylation (Fig. 6). In contrast, scrape-loading cells with N17Cdc42 significantly attenuated mAChR-induced FAK phosphorylation by 35 $\pm 12 \%$ (Fig. $6 ; \mathrm{n}=4, p<0.05$ ). Thus, the $\mathrm{M}_{3} \mathrm{mAChR}$ signals to FAK through both Rho and Cdc42.

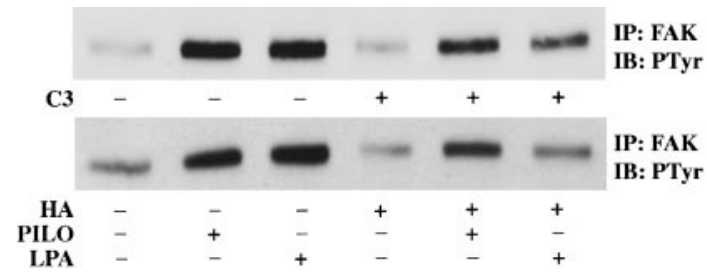

FIG. 5. Differential sensitivity of PILO- and LPA-stimulated FAK phosphorylation to inhibition by either C3 exoenzyme or HA1077. SH-SY5Y cells were preincubated with either scrapeloaded C3 exoenzyme (upper panel) or HA-1077 (lower panel) exactly as described in the legend to Fig. 4 . The cells were then incubated for a further 10 min with either buffer, PILO (1 mM), or LPA $(10 \mu M)$. FAK immune complexes were immunoblotted (IB) for PTyr. IP, immunoprecipitated.

Tox B has little effect on phosphoinositide turnover or agonist-sensitive pools of PIP $_{2}$ in SH-SY5Y neuroblastoma cells

The small molecular weight $\mathrm{G}$ proteins Rho and Rac have each been shown to regulate the synthesis of $\mathrm{PIP}_{2}$ in fibroblasts (Chong et al., 1994) and platelets (Hartwig et al., 1995), respectively. Moreover, Tox B treatment has been shown to decrease the concentration of $\mathrm{PIP}_{2}$ in several cell lines and, as a result, to inhibit the phospho-

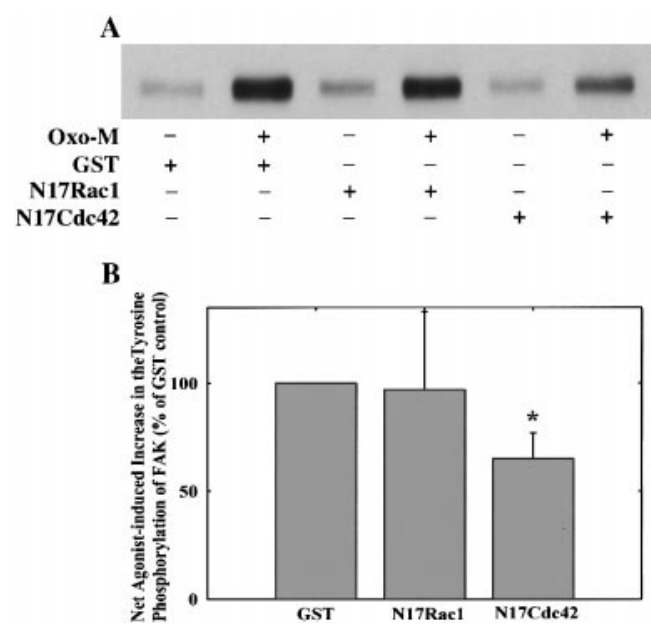

FIG. 6. Effects of scrape-loaded GST-N17Rac1 and GSTN17Cdc42 on mAChR-mediated FAK phosphorylation. A: Confluent cultures of SH-SY5Y cells were scrape-loaded with either GST alone, GST-N17Rac1, or GST-N17Cdc42 (each at a concentration of $20 \mu \mathrm{g} / \mathrm{ml}$ ), as described in Experimental Procedures. After 30 min of preincubation, the cells were incubated for a further $10 \mathrm{~min}$ with either buffer or $1 \mathrm{mM}$ Oxo-M. Cells were homogenized in lysis buffer, and supernatants were immunoprecipitated (IP) with polyclonal anti-FAK. Immune complexes were resolved by SDS-PAGE, transferred to PVDF, and immunoblotted (IB) for PTyr. B: Densitometric analysis of FAK tyrosine phosphorylation was performed. The results are expressed as a percentage of the net increase in FAK phosphorylation induced by Oxo-M in cells scrape-loaded with GST alone and represent the means \pm SEM of four independent experiments. Addition of Oxo-M increased the tyrosine phosphorylation of FAK in GST control cells from $0.18 \pm 0.06$ to $0.66 \pm 0.07$ O.D. unit. ${ }^{*} p$ $<0.05$, significantly different from the GST control. 
lipase C-dependent generation of inositol phosphates in these cells (Schmidt et al., 1996; Zhang et al., 1996; Rümenapp et al., 1998). Given the dependence of mAChR-stimulated FAK phosphorylation on agonistsensitive pools of $\mathrm{PIP}_{2}$ (Linseman et al., 1999) and Rho family $\mathrm{G}$ proteins (see above), it was important to determine if Rho family $G$ proteins are critical regulators of $\mathrm{PIP}_{2}$ synthesis in SH-SY5Y cells. First, we analyzed the effects of preincubation with Tox B on inositol lipid concentrations and Oxo-M-stimulated phosphoinositide turnover in $\left[{ }^{3} \mathrm{H}\right]$ inositol-prelabeled SH-SY5Y cells. Tox $\mathrm{B}$, at the same concentrations that significantly inhibited mAChR signaling to FAK and paxillin, had no significant effect on the concentrations of either phosphatidylinositol (PI), phosphatidylinositol 4-phosphate (PIP), or $\mathrm{PIP}_{2}$ under basal conditions (Fig. 7A). Furthermore, preincubation with Tox B had little effect on the agoniststimulated production of ${ }^{3} \mathrm{H}$-inositol phosphates $(20 \%$ inhibition at $200 \mathrm{pg} / \mathrm{ml}$; Fig. 7B). This small decrease in the release of inositol phosphates observed at the highest concentration of Tox B was correlated with a small but significant $(p<0.05)$ decrease in $\left[{ }^{3} \mathrm{H}\right] \mathrm{PIP}_{2}(61 \pm 1 \%$ of control; $\mathrm{n}=3$ ) compared with cells treated with agonist alone $(81 \pm 5 \%$ of control; $n=3)$. This latter result suggests that there may be some Rho GTPase-dependent regulation of inositol lipid synthesis that occurs in response to agonist challenge.

To further address this possibility, we next investigated if Tox B may have a selective effect on agonistsensitive pools of inositol lipids by comparing the effects of Tox B on ${ }^{32} \mathrm{P}$-lipid labeling with those observed with WT at a concentration $(10 \mu M)$ that inhibits phosphatidylinositol 4-kinase activity and, as a consequence, blocks phosphoinositide turnover in this cell line (Linseman et al., 1998; Sorensen et al., 1998; Willars et al., 1998). As previously described (Linseman et al., 1999), Oxo-M stimulation of ${ }^{32} \mathrm{P}$-prelabeled SH-SY5Y cells for 10 min results in an $\sim 50 \%$ reduction in the labeling of $\left[{ }^{32} \mathrm{P}\right] \mathrm{PIP}_{2}$ (Fig. 8A) and a $250 \%$ increase in $\left[{ }^{32} \mathrm{P}\right]$ phosphatidic acid ([ $\left.\left.{ }^{32} \mathrm{P}\right] \mathrm{PA}\right)$ (Fig. 8B). Preincubation with WT significantly potentiated the agonist-induced decrease in $\left.{ }^{32} \mathrm{P}\right] \mathrm{PIP}{ }_{2}$ due to its ability to block phosphoinositide resynthesis (Fig. 8A). As a result of the depletion of $\mathrm{PIP}_{2}$ pools, WT pretreatment also resulted in a profound inhibition of the agonist-stimulated production of $\left[{ }^{32} \mathrm{P}\right] \mathrm{PA}$ (Fig. $8 \mathrm{~B}$ ). In marked contrast to the pronounced effects on phosphoinositide turnover observed with WT, Tox B had no significant effects on either the agonist-driven decrease in $\left.{ }^{32} \mathrm{P}\right] \mathrm{PIP}_{2}$ (Fig. 8A) or the increase in $\left.{ }^{32} \mathrm{P}\right] \mathrm{PA}$ (Fig. $8 \mathrm{~B}$ ). Taken collectively, the above results suggest that in the SH-SY5Y cell line, Rho family $\mathrm{G}$ proteins play only a minor role, if any, in the regulation of mAChR-sensitive inositol lipid pools.

\section{Tox B inhibits mAChR-mediated remodeling of the actin cytoskeleton}

Rho family $\mathrm{G}$ proteins regulate the dynamics of the actin cytoskeleton (Hall, 1998) including neuronal growth cone remodeling (Threadgill et al., 1997).
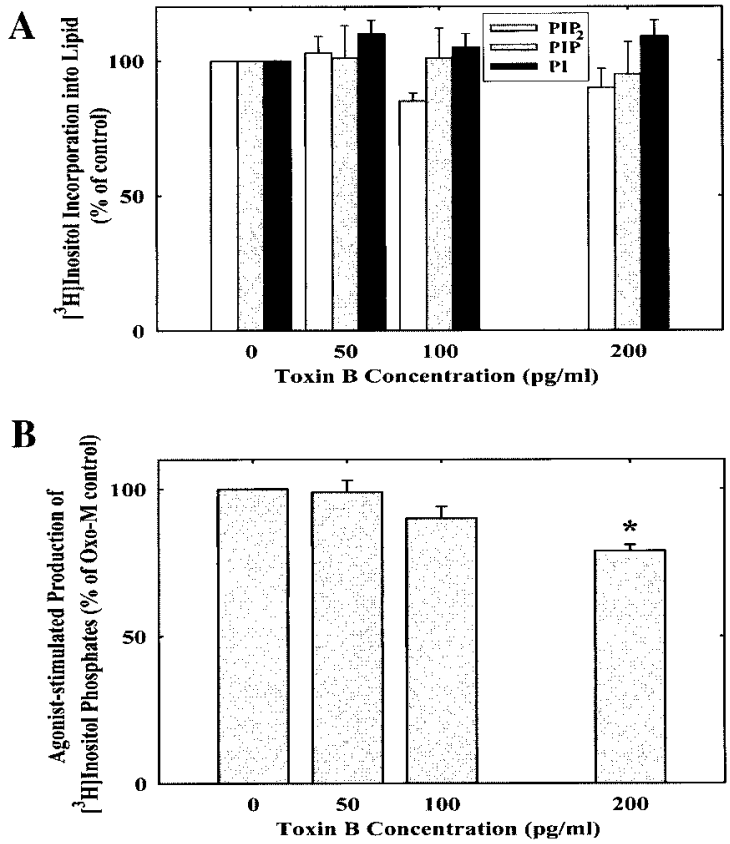

FIG. 7. Tox $B$ has minimal effects on $\left[{ }^{3} \mathrm{H}\right]$ inositol lipid labeling and mAChR-stimulated phosphoinositide turnover in SH-SY5Y neuroblastoma cells. Confluent flasks of SH-SY5Y cells were prelabeled with myo- $\left[2-{ }^{3} \mathrm{H}\right]$ inositol for $48 \mathrm{~h}$ followed by a further 24-h incubation in culture medium containing $\left[{ }^{3} \mathrm{H}\right]$ inositol and either vehicle ( $0.1 \%$ BSA in PBS) or the indicated concentrations of Tox B. A: Following incubation, lipids from a total of $\sim 1 \mathrm{mg}$ of cell protein per sample were extracted and separated by TLC, and the radioactivity incorporated into $\mathrm{PI}, \mathrm{PIP}$, and $\mathrm{PIP}_{2}$ was quantified. The results are expressed as a percentage of the label incorporated into lipid extracted from cells treated with vehicle and represent the means \pm SEM of three independent experiments. The total amount of $\left[{ }^{3} \mathrm{H}\right]$ inositol incorporated into lipids extracted from vehicle-treated cells was 585,551 $\pm 34,524,10,240 \pm 759$, and $3,481 \pm 322 \mathrm{dpm} / \mathrm{mg}$ of protein for $\mathrm{PI}, \mathrm{PIP}$, and $\mathrm{PIP}_{2}$, respectively. B: $\left[{ }^{3} \mathrm{H}\right]$ Inositol-prelabeled cells were preincubated with either vehicle or Tox $\mathrm{B}$ as described above and then treated with either buffer or Oxo-M (1 mM) for 30 min in the presence of $30 \mathrm{mM} \mathrm{LiCl}$. The agonist-stimulated production of ${ }^{3} \mathrm{H}$-inositol phosphates was analyzed as described in Experimental Procedures. The results are expressed as a percentage of the inositol phosphates released from vehiclepretreated cells following agonist stimulation and represent the means \pm SEM of three independent experiments, each performed in triplicate. In vehicle-pretreated cells, Oxo-M addition stimulated a $54.8 \pm 0.9$-fold increase in inositol phosphate production over the basal level. ${ }^{*} p<0.05$, significantly different from the control.

Moreover, Tox B treatment has been shown to disrupt the actin cytoskeleton (Just et al., 1995). Given that $\mathrm{mAChR}$ signaling to FAK is dependent on an intact actin cytoskeleton (Linseman et al., 1998), we analyzed the effects of preincubation with Tox B on mAChRmediated cytoskeletal remodeling in SH-SY5Y cells. As previously reported (Rösner et al., 1995), incubation of SH-SY5Y neuroblastoma cells with an mAChR agonist elicits the rapid formation of large lamellipodia and prominent membrane ruffles (Fig. 9A and B). In addition, we also observed an agonist-induced increase in the 
A

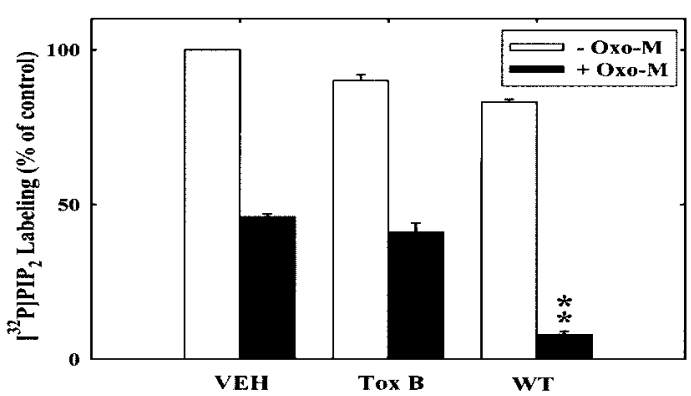

B

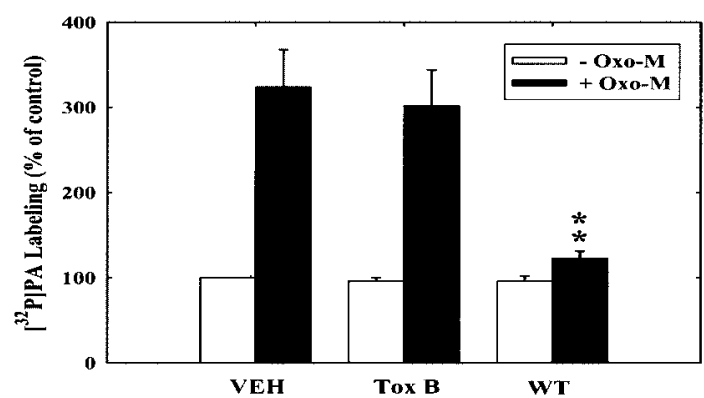

FIG. 8. Comparison of Tox B and WT effects on Oxo-M-stimulated phosphoinositide turnover in ${ }^{32} \mathrm{P}$-prelabeled $\mathrm{SH}-\mathrm{SY} 5 \mathrm{Y}$ cells. Confluent cultures of $\mathrm{SH}-\mathrm{SY} 5 \mathrm{Y}$ cells were preincubated for $\sim 24 \mathrm{~h}$ in culture medium containing either vehicle (VEH; $0.1 \%$ BSA in PBS) or Tox B $(200 \mathrm{pg} / \mathrm{ml})$. Cells were then labeled for 2-4 $\mathrm{h}$ with ${ }^{32} \mathrm{P}_{\mathrm{i}}$ as described in Experimental Procedures. Following labeling, some cultures were preincubated for $10 \mathrm{~min}$ with $10 \mu \mathrm{M}$ WT, and the cells were then treated for a further 10 min with either buffer or Oxo-M (1 mM). Incubations were terminated by aspiration of the treatment solution and rapid addition of TCA. Lipids were then extracted and separated by TLC, and the radioactivity incorporated into $\mathrm{PIP}_{2}(\mathbf{A})$ and $\mathrm{PA}(\mathbf{B})$ was quantified. The results are expressed as a percentage of the label incorporated into lipid extracted from cells treated with buffer and represent the means \pm SEM of three independent experiments, each performed in duplicate. ${ }^{* *} p<0.01$, significantly different from Oxo-M + vehicle.

apparent thickness and number of actin stress fibers (Fig. 9A and B). Preincubation with Tox B induced a disruption of the actin cytoskeleton and cell rounding (Fig. 9C). Tox $\mathrm{B}$ also inhibited the agonist-driven changes in actin cytoskeletal structure (Fig. 9D). These results suggest that Rho family $\mathrm{G}$ proteins act as critical regulators of actin cytoskeletal integrity in SH-SY5Y neuroblastoma cells.

\section{DISCUSSION}

Previous work has demonstrated a requirement for Rho in signaling from several phosphoinositide-linked GPCRs to FAK, including receptors for bombesin and endothelin (Rankin et al., 1994) and sphingolipids (Seufferlein and Rozengurt, 1995). However, a role for Rho GTPases in mAChR signaling to FAK has not previously been demonstrated (see Seasholtz et al., 1999). In the current study, we utilized highly selective inhibitors of Rho family GTPase function to demonstrate a requirement for these small molecular weight $\mathrm{G}$ proteins in mAChR signaling to FAK. Preincubation with $C$. difficile Tox $\mathrm{B}$, at concentrations that effectively altered Rho family G proteins in intact SH-SY5Y neuroblastoma cells (Fig. 1), significantly inhibited mAChR-mediated increases in the tyrosine phosphorylation of both FAK and paxillin (Fig. 2). The inhibitory effects of Tox B showed selectivity for agonist-stimulated FAK and paxillin phosphorylation, as mAChR- or PKC-mediated MAPK activation was unaffected (Fig. 3). In addition, SH-SY5Y cells preincubated with either $C$. botulinum C3 exoenzyme or the Rho kinase inhibitor HA-1077 also showed a partial inhibition of mAChR-stimulated FAK phosphorylation (Figs. 4 and 5). Finally, scrape-loading cells with dominant-negative N17Cdc42 significantly attenuated mAChR-mediated FAK phosphorylation (Fig. 6).

Although both Tox B and C3 exoenzyme have the potential to significantly disrupt actin cytoskeletal structure (see Fig. 9 and Seufferlein and Rozengurt, 1995, respectively), the inhibitory effects of these agents on $\mathrm{mAChR}$-mediated FAK phosphorylation are likely to occur upstream of this gross effect. mAChRs have been shown to signal to both Rho (Keller et al., 1997) and Rac/Cdc42 (Kozma et al., 1997). Furthermore, scrapeloading cells with constitutively active Rho has been shown to stimulate an increase in FAK phosphorylation (Flinn and Ridley, 1996). These results suggest a signaling cascade in which mAChR stimulation leads to the activation of Rho family GTPases, which in turn elicit changes in actin cytoskeletal structure and FAK phosphorylation. Therefore, inhibition of Rho family GTPase function with either Tox B or C3 exoenzyme produces inhibitory effects on multiple downstream elements of this signaling pathway (i.e., both an inhibition of FAK phosphorylation and a disruption of the actin cytoskeleton). In addition, it should also be noted that we observed a significant attenuation of mAChR-mediated FAK phosphorylation in cells scrape-loaded with dominant-negative Cdc42 (see Fig. 6). This latter agent has been shown to have no gross effects on actin cytoskeletal integrity but rather specifically inhibits the formation of filopodia (Kozma et al., 1995). Thus, the above results are the first to implicate the Rho family GTPases, Rho and Cdc42, in mAChR signaling to FAK.

Although the enhanced tyrosine phosphorylation of FAK elicited by LPA was equally susceptible to inhibition by either Tox B (an inhibitor of Rho, Rac, and Cdc42) or C3 exoenzyme (a specific inhibitor of Rho), mAChRstimulated FAK phosphorylation was much more sensitive to inhibition by Tox B than C3 exoenzyme (Fig. 4B). Furthermore, LPA- and mAChR-stimulated FAK phosphorylation also showed a differential sensitivity to inhibition by the Rho kinase inhibitor HA-1077, which, like C3 exoenzyme, only partially inhibited mAChRinduced FAK phosphorylation (Fig. 4B). Similar differential effects were observed whether the LPA-induced FAK phosphorylation was compared with that stimulated by a full mAChR agonist (Fig. 4) or a partial mAChR 

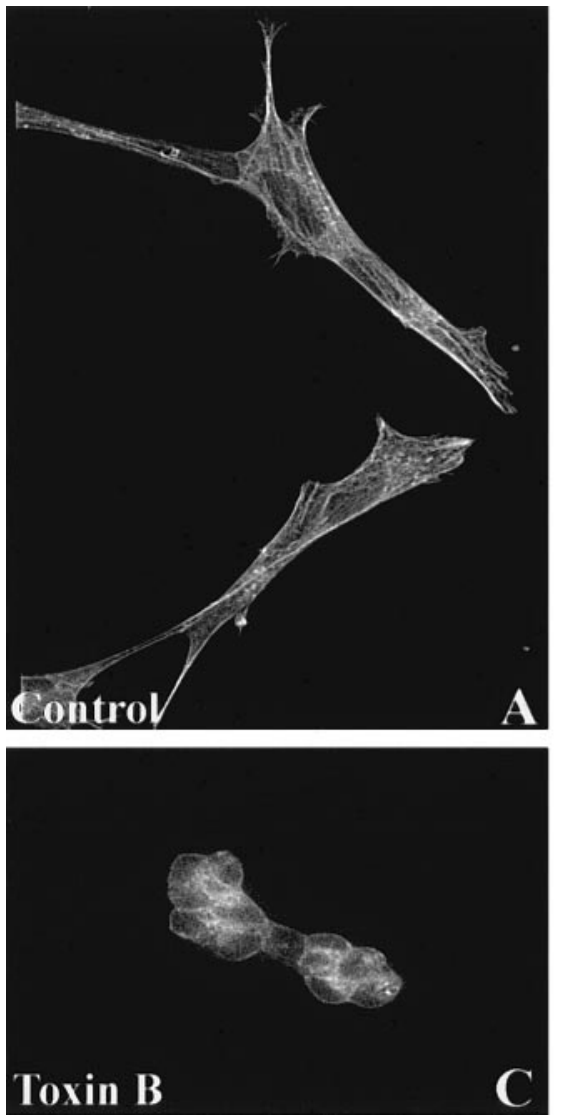
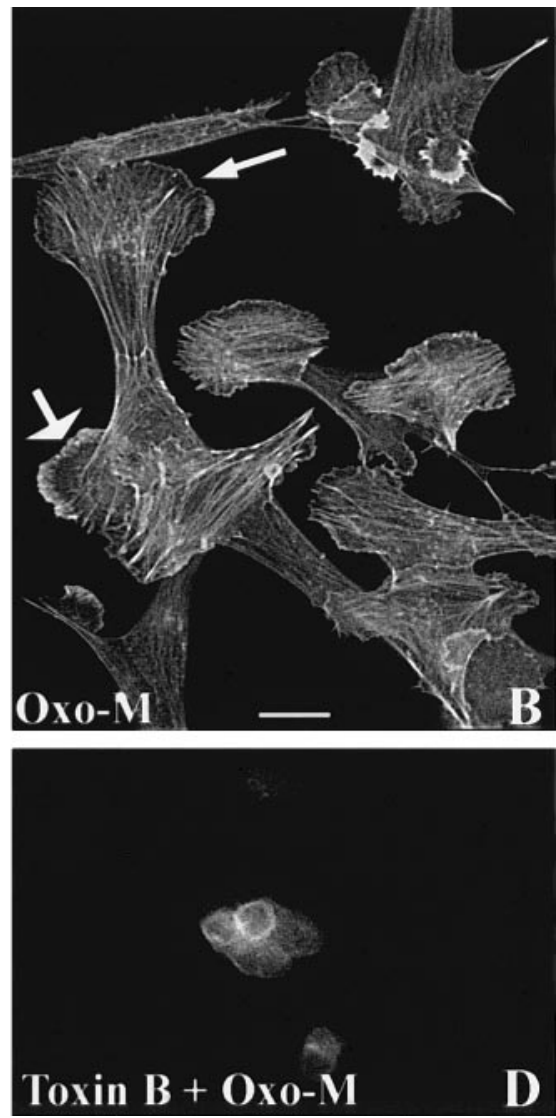

FIG. 9. Effects of Tox B on mAChRstimulated remodeling of the actin cytoskeleton. SH-SY5Y cells were preincubated for $\sim 24 \mathrm{~h}$ in culture medium containing either vehicle (0.1\% BSA in PBS) (A and B) or $200 \mathrm{pg} / \mathrm{ml}$ Tox B (C and D). The cells were then treated for 5 min with either buffer ( $A$ and $C$ ) or $1 \mathrm{mM}$ Oxo-M ( $B$ and $D$ ). Following treatment, the cells were fixed with paraformaldehyde and permeabilized with Triton X-100, and Factin was stained with rhodamine/phalloidin, as described in Experimental Procedures. The images shown are representative of two independent experiments that demonstrated similar results. In $\mathrm{B}$, the thin arrow indicates a lamellipodium and the wide arrow points to a membrane ruffle. Bar $=10 \mu \mathrm{m}$. agonist (Fig. 5). These data suggested that Rho and its downstream effectors may not be the only small molecular weight $G$ protein signaling cascade capable of coupling receptor activation to FAK phosphorylation. This suggestion was confirmed by the observation that N17Cdc42, but not N17Rac1, significantly attenuated mAChR-stimulated FAK phosphorylation (Fig. 6). This result is in agreement with a previous study in fibroblasts that showed that scrape-loading of constitutively active Rho, but not Rac, increased the tyrosine phosphorylation of FAK (Flinn and Ridley, 1996). Moreover, a recent report has described a novel signaling pathway linking Cdc42 activation to the tyrosine phosphorylation of p130 ${ }^{\text {Cas }}$, a putative downstream substrate of FAK (Eisenmann et al., 1999). Our observation that Cdc42 regulates mAChR signaling to FAK is consistent with this latter finding.

We have previously demonstrated that an increased tyrosine phosphorylation of FAK elicited by a mechanistically diverse array of stimuli requires the maintenance of agonist-sensitive pools of $\mathrm{PIP}_{2}$ (Linseman et al., 1999). Other researchers have shown that $\mathrm{PIP}_{2}$ synthesis is regulated by Rho family GTPases (Carpenter, 1996; Ren and Schwartz, 1998), although the particular Rho family member involved is probably cell type-specific (Chong et al., 1994; Hartwig et al., 1995). An unexpected result to emanate from the present study is the observation that inhibition of Rho family $G$ protein function with
Tox B significantly attenuates FAK signaling in SHSY5Y neuroblastoma cells without effectively altering $\mathrm{PIP}_{2}$ synthesis or agonist-stimulated phosphoinositide turnover (see Figs. 7 and 8). This finding is in contrast to results obtained in either HEK cells stably transfected with the $\mathrm{M}_{3}$ mAChR (Schmidt et al., 1996; Rümenapp et al., 1998) or N1E-115 mouse neuroblastoma cells (Zhang et al., 1996) in which Tox B treatment selectively decreased $\mathrm{PIP}_{2}$ concentrations and significantly inhibited agonist-stimulated phosphoinositide turnover. The differences observed between these latter studies and the present investigation may reflect differences in the isoforms of the phosphoinositide kinases expressed in each cell type and whether or not they are under equivalent regulation by Rho family GTPases. Although the results obtained with Tox B in the present study provide additional evidence that regulation of inositol lipid synthesis by the Rho family $\mathrm{G}$ proteins is cell type-specific, more importantly they effectively dissociate the Rho GTPasedependent regulation of $\mathrm{PIP}_{2}$ synthesis from the Rho GTPase-dependent regulation of FAK signaling. Moreover, agonist-stimulated actin cytoskeletal remodeling was also inhibited by Tox B at concentrations that had little to no effect on inositol lipid synthesis (Fig. 9). Although we cannot exclude the possibility that a small, highly compartmentalized lipid pool under the regulation of Rho GTPases modulates the actin cytoskeleton, the above results suggest that the ability of Rho family $G$ 
proteins to effect changes in the actin cytoskeleton via a modulation of $\mathrm{PIP}_{2}$ synthesis, as previously demonstrated in platelets (Hartwig et al., 1995), may not be a principal mechanism for cytoskeletal remodeling in other cell types.

In summary, we have shown that the Rho family $G$ proteins, Rho and $\mathrm{Cdc} 42$, are both required for $\mathrm{mAChR}$ signaling to FAK in SH-SY5Y neuroblastoma cells. Although agonist-sensitive pools of $\mathrm{PIP}_{2}$ are also required for $\mathrm{mAChR}$ signaling to FAK, this prerequisite is independent of regulation by Rho family GTPases. The results suggest that there are several independent regulatory pathways that are each capable of coupling receptor activation to changes in growth cone remodeling and FAK activation in neuronal cells.

Acknowledgment: The authors thank Ms. Jo Ann Kelsch and Mr. Tim Desmond for preparation of the manuscript. The authors also thank Drs. Stephen Ernst and Klaus Aktories for their helpful suggestions. This work was supported by National Institutes of Health grants NS23831 (to S.K.F.) and MH12193F31 (to D.A.L.). D.A.L. was also supported by National Institutes of Health Training Grant GM07767.

\section{REFERENCES}

Aktories K., Braun U., Rosener S., Just I., and Hall A. (1989) The Rho gene product expressed in E. coli is a substrate of botulinum ADP-ribosyltransferase C3. Biochem. Biophys. Res. Commun. 158, 209-213.

Beggs H. E., Baragona S. C., Hemperly J. J., and Maness P. F. (1997) NCAM140 interacts with the focal adhesion kinase $125^{\text {fak }}$ and the SRC-related tyrosine kinase $55^{f y n}$. J. Biol. Chem. 272, 83108319.

Boxall A. R., Lancaster B., and Garthwaite J. (1996) Tyrosine kinase is required for long-term depression in the cerebellum. Neuron 16, 805-813.

Braun U., Habermann B., Just I., Aktories K., and Vandekerckhove J. (1989) Purification of the $22 \mathrm{kDa}$ protein substrate of botulinum ADP-ribosyltransferase C3 from porcine brain cytosol and its characterization as a GTP-binding protein highly homologous to the Rho gene product. FEBS Lett. 243, 70-76.

Burgaya F., Menegon A., Menegoz M., Valtorta F., and Girault J.-A. (1995) Focal adhesion kinase in rat central nervous system. Eur. J. Neurosci. 7, 1810-1821.

Carpenter C. L. (1996) Intracellular signals and the cytoskeleton: the interactions of phosphoinositide kinases and small $\mathrm{G}$ proteins in adherence, ruffling and motility. Semin. Cell Dev. Biol. 7, 691697.

Chong L. D., Traynor-Kaplan A., Bokoch G. M., and Schwartz M. A. (1994) The small GTP-binding protein Rho regulates a phosphatidylinositol 4-phosphate 5-kinase in mammalian cells. Cell 79, 507-513.

Eisenmann K. M., McCarthy J. B., Simpson M. A., Keely P. J., Guan J.-L., Tachibana K., Lim L., Manser E., Furcht L. T., and Iida J. (1999) Melanoma chondroitin sulphate proteoglycan regulates cell spreading through Cdc42, Ack-1 and p130 cas. Nat. Cell Biol. 1, 507-513.

Fisher S. K. and Agranoff B. W. (1980) Calcium and the muscarinic synaptosomal phospholipid labeling effect. J. Neurochem. 34, 1231-1240.

Fisher S. K., Figueiredo J. C., and Bartus R. T. (1984) Differential stimulation of inositol phospholipid turnover in brain by analogs of oxotremorine. J. Neurochem. 43, 1171-1179.

Flinn H. M. and Ridley A. J. (1996) Rho stimulates tyrosine phosphorylation of focal adhesion kinase, p130 and paxillin. J. Cell Sci. 109, 1133-1141.
Girault J.-A., Costa A., Derkinderen P., Studler J.-M., and Toutant M. (1999) FAK and PYK2/CAK $\beta$ in the nervous system: a link between neuronal activity, plasticity and survival? Trends Neurosci. 22, 257-263.

Hall A. (1998) Rho GTPases and the actin cytoskeleton. Science 279, $509-514$.

Hartwig J. H., Bokoch G. M., Carpenter C. L., Janmey P. A., Taylor L. A., Toker A., and Stossel T. P. (1995) Thrombin receptor ligation and activated Rac uncap actin filament barbed ends through phosphoinositide synthesis in permeabilized human platelets. Cell 82, 643-653.

Just I., Fritz G., Aktories K., Giry M., Popoff M. R., Boquet P., Hegenbarth S., and von Eichel-Streiber C. (1994) Clostridium difficile toxin B acts on the GTP-binding protein Rho. J. Biol. Chem. 269, 10706-10712.

Just I., Seizer J., Wilm M., von Eichel-Streiber C., Mann M., and Aktories K. (1995) Glucosylation of Rho proteins by Clostridium difficile toxin B. Nature 375, 500-503.

Keller J., Schmidt M., Hussein B., Rümenapp U., and Jakobs K. H. (1997) Muscarinic receptor-stimulated cytosol-membrane translocation of RhoA. FEBS Lett. 403, 299-302.

Kozma R., Ahmed S., Best A., and Lim L. (1995) The Ras-related protein $\mathrm{Cdc} 42 \mathrm{Hs}$ and bradykinin promote formation of peripheral actin microspikes and filopodia in Swiss 3T3 fibroblasts. Mol. Cell. Biol. 15, 1942-1952.

Kozma R., Sarner S., Ahmed S., and Lim L. (1997) Rho family GTPases and neuronal growth cone remodelling: relationship between increased complexity induced by $\mathrm{Cdc} 42 \mathrm{Hs}$, Rac1, and acetylcholine and collapse induced by RhoA and lysophosphatidic acid. Mol. Cell. Biol. 17, 1201-1211.

Kranenburg O., Poland M., von Horck F. P. G., Drechsel D., Hall A., and Moolenaar W. H. (1999) Activation of RhoA by lysophosphatidic acid and $\mathrm{G} \alpha_{12 / 13}$ subunits in neuronal cells: induction of neurite retraction. Mol. Biol. Cell 10, 1851-1857.

Kumagai N., Morii N., Fujisawa K., Nemoto Y., and Narumiya S. (1993) ADP-ribosylation of rho p21 inhibits lysophosphatidic acid-induced protein tyrosine phosphorylation and phosphatidylinositol 3-kinase activation in cultured Swiss 3 T3 cells. J. Biol. Chem. 268, 24535-24538.

Leventhal P. S., Shelden E. A., Kim B., and Feldman E. L. (1997) Tyrosine phosphorylation of paxillin and focal adhesion kinase during insulin-like growth factor-I-stimulated lamellipodial advance. J. Biol. Chem. 272, 5214-5218.

Linseman D. A., McEwen E. L., Sorensen S. D., and Fisher S. K. (1998) Cytoskeletal and phosphoinositide requirements for muscarinic receptor signaling to focal adhesion kinase and paxillin. J. Neurochem. 70, 940-950.

Linseman D. A., Sorensen S. D., and Fisher S. K. (1999) Attenuation of focal adhesion kinase signaling following depletion of agonistsensitive pools of phosphatidylinositol 4,5-bisphosphate. J. Neurochem. 73, 1933-1944.

Luo L., Jan L., and Jan Y. N. (1996) Small GTPases in axon outgrowth. Perspect. Dev. Neurobiol. 4, 199-204.

Mackay D. J. G. and Hall A. (1998) Rho GTPases. J. Biol. Chem. 273, 20685-20688.

Maekawa M., Ishizaki T., Boku S., Watanabe N., Fujita A., Iwamatsu A., Obinata T., Ohashi K., Mizuno K., and Narumiya S. (1999) Signaling from Rho to the actin cytoskeleton through protein kinases ROCK and LIM-kinase. Science 285, 895-898.

Martin T. F. J. (1998) Phosphoinositide lipids as signaling molecules: common themes for signal transduction, cytoskeletal regulation, and membrane trafficking. Аnпи. Rev. Cell Dev. Biol. 14, 231264.

O’Dell T. J., Kandel E. R., and Grant S. G. N. (1991) Long-term potentiation in the hippocampus is blocked by tyrosine kinase inhibitors. Nature 353, 558-560.

Offermanns S., Bombien E., and Schultz G. (1993) Stimulation of tyrosine phosphorylation and mitogen-activated-protein (MAP) kinase activity in human SH-SY5Y neuroblastoma cells by carbachol. Biochem. J. 294, 545-550.

Rankin S., Morii N., Narumiya S., and Rozengurt E. (1994) Botulinum C3 exoenzyme blocks the tyrosine phosphorylation of $\mathrm{p} 125^{\mathrm{FAK}}$ 
and paxillin induced by bombesin and endothelin. FEBS Lett. 354, 315-319.

Ren X.-D. and Schwartz M. A. (1998) Regulation of inositol lipid kinases by Rho and Rac. Curr. Opin. Genet. Dev. 8, 63-67.

Rösner H., Vacun G., and Rebhan M. (1995) Muscarinic receptormediated induction of actin-driven lamellar protrusions in neuroblastoma cell somata and growth cones. Involvement of protein kinase C. Eur. J. Cell Biol. 66, 324-334.

Rümenapp U., Schmidt M., Olesch S., Ott S., von Eichel-Streiber C., and Jakobs K. H. (1998) Tyrosine-phosphorylation-dependent and Rho-protein-mediated control of cellular phosphatidylinositol 4,5bisphosphate levels. Biochem. J. 334, 625-631.

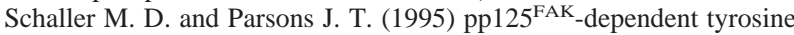
phosphorylation of paxillin creates a high-affinity binding site for Crk. Mol. Cell. Biol. 15, 2635-2645.

Schlaepfer D. D., Hanks S. K., Hunter T., and van der Geer P. (1994) Integrin-mediated signal transduction linked to Ras pathway by GRB2 binding to focal adhesion kinase. Nature 372, 786-791.

Schmidt M., Bienek C., Rümenapp U., Zhang C., Lümmen G., Jakobs K. H., Just I., Aktories K., Moos M., and von Eichel-Streiber C. (1996) A role for Rho in receptor- and G protein-stimulated phospholipase C. Reduction in phosphatidylinositol 4,5-bisphosphate by Clostridium difficile toxin B. Naunyn Schmiedebergs Arch. Pharmacol. 354, 87-94.

Seasholtz T. M., Majumdar M., and Brown J. H. (1999) Rho as a mediator of G protein-coupled receptor signaling. Mol. Pharmacol. 55, 949-956.

Seufferlein T. and Rozengurt E. (1995) Sphingosylphosphorylcholine rapidly induces tyrosine phosphorylation of $\mathrm{p} 125^{\mathrm{FAK}}$ and paxillin, rearrangement of the actin cytoskeleton and focal contact assembly. Requirement of $\mathrm{p} 21^{\text {rho }}$ in the signaling pathway. J. Biol. Chem. 270, 24343-24351.

Sorensen S. D., Linseman D. A., McEwen E. L., Heacock A. M., and Fisher S. K. (1998) A role for a wortmannin-sensitive phosphati- dylinositol-4-kinase in the endocytosis of muscarinic cholinergic receptors. Mol. Pharmacol. 53, 827-836.

Thompson A. K. and Fisher S. K. (1990) Relationship between agonistinduced muscarinic receptor loss and desensitization of stimulated phosphoinositide turnover in two neuroblastomas: methodological considerations. J. Pharmacol. Exp. Ther. 252, 744-752.

Threadgill R., Bobb K., and Ghosh A. (1997) Regulation of dendritic growth and remodeling by Rho, Rac, and Cdc42. Neuron 19, $625-634$.

Toker A. (1998) The synthesis and cellular roles of phosphatidylinositol 4,5-bisphosphate. Curr. Opin. Cell Biol. 10, 254-261.

Uehata M., Ishizaki T., Satoh H., Ono T., Kawahara T., Morishita T., Tamakawa H., Yamagami K., Inui J., Maekawa M., and Narumiya S. (1997) Calcium sensitization of smooth muscle mediated by a Rho-associated protein kinase in hypertension. Nature 389, $990-$ 994.

Willars G. B., Nahorski S. R., and Challiss R. A. J. (1998) Differential regulation of muscarinic acetylcholine receptor-sensitive polyphosphoinositide pools and consequences for signaling in human neuroblastoma cells. J. Biol. Chem. 273, 5037-5046.

Worley T. L. and Holt C. E. (1996) Expression and herbimycin Asensitive localization of pp125FAK in retinal growth cones. Neuroreport 7, 1133-1137.

Yamamoto M., Marui N., Sakai T., Morii N., Kozaki S., Ikai K., Imamura S., and Narumiya S. (1993) ADP-ribosylation of the rhoA gene product by botulinum C3 exoenzyme causes Swiss 3T3 cells to accumulate in the $\mathrm{G}_{1}$ phase of the cell cycle. Oncogene $\mathbf{8}$, 1449-1455.

Zhang C., Schmidt M., von Eichel-Streiber C., and Jakobs K. H. (1996) Inhibition by toxin $\mathrm{B}$ of inositol phosphate formation induced by G protein-coupled and tyrosine kinase receptors in N1E-115 neuroblastoma cells: involvement of Rho proteins. Mol. Pharmacol. 50, $864-869$. 